\title{
Preoperative Rectal Cancer Management: Wide International Practice Makes Outcome Comparison Challenging: Reply
}

\author{
Knut M. Augestad $\cdot$ Rolv-Ole Lindsetmo $\cdot$ Jonah Stulberg $•$ \\ Harry Reynolds • Brad Champagne - Fabien Leblanc • \\ Alexander G. Heriot • Anthony Senagore • Conor Delaney
}

Published online: 1 April 2011

(c) The Author(s) 2011. This article is published with open access at Springerlink.com

In a letter to the editor Dr. Hottenrott provides valuable comments [1] on our survey describing international preoperative rectal cancer management [2]. In our opinion, three key messages are derived from our survey: First, most surgeons agree to neoadjuvant treatment when there is an increased risk of finding histologically positive circumferential margins. In addition, we found more than 40 other indications for neoadjuvant treatment (see our Table 4). This emphasizes the need for an international agreement, as different indications for neoadjuvant treatment will select noncomparable groups of patients in outcome studies.

Second, we have shown (see our Table 6) that multidisciplinary team (MDT) meetings significantly influence several important decisions in preoperative rectal cancer management. Interestingly, centers with regular MDT have a higher rate of using magnetic resonance imaging (MRI) (Odds Ratio $[\mathrm{OR}]=3.62$ ) and consider a threatened circumferential resection margin (CRM) as indication for

K. M. Augestad - J. Stulberg - H. Reynolds - B. Champagne ·

C. Delaney $(\bowtie)$

Division of Colorectal Surgery, University Hospitals Case

Medical Center, 11100 Euclid Avenue, Cleveland,

OH 44106-5047, USA

e-mail: conor.delaney@UHhospitals.org

K. M. Augestad · R.-O. Lindsetmo

Department of Gastrointestinal Surgery,

University Hospital of North Norway, Troms $\varnothing$, Norway

R.-O. Lindsetmo

Institute of Clinical Medicine, Troms $\varnothing$ University,

Troms $\varnothing$, Norway

K. M. Augestad

Department of Telemedicine and Health Service Research,

University Hospital of North Norway, Troms $\varnothing$, Norway neoadjuvant treatment $(\mathrm{OR}=5.67)$. We believe that MDT improves preoperative management of rectal cancer by increasing adherence to national guidelines. Similar discussions in international rectal cancer societies are needed aiming towards an international consensus statement.

Finally, our survey revealed sparse use $(35 \%$ of all cases) of MRI. The goal for the radiologic examination in rectal cancer is to explore the tumor's relation to nearby anatomical structures. This evaluation will conclude with TNM staging, important for chemoradiotheraphy, surgical treatment, and prognosis. Magnetic resonance imaging has a central role in this evaluation and should be the first choice radiologic modality [3]. Not only is MRI crucial in detection of TNM stage but also plays a central role in determination of the tumor's distance to the mesorectal fascia and the CRM. Magnetic resonance imaging has moderate sensitivity on $\mathrm{T} 1$ and $\mathrm{T} 2$ tumors, and should be supplemented with rectal ultrasound.

\author{
J. Stulberg \\ Department of Biostatistics and Epidemiology, \\ School of Medicine, Case Western Reserve University, \\ Cleveland, $\mathrm{OH}$, USA \\ F. Leblanc \\ Department of Digestive Surgery, \\ University Hospitals of Bordeaux, Bordeaux, France
}

A. G. Heriot

Division of Surgical Oncology, Peter MacCallum Cancer Centre,

Melbourne, VIC, Australia

A. Senagore

Department of Surgery, USC Norris Cancer Hospital,

University of Southern California, Los Angeles, CA, USA 
In our survey, ${ }^{18} \mathrm{~F}$-fluorodeoxyglucose positron emission tomography (PET) was used by $55 \%$ in selected cases and by $1 \%$ in all cases. In our opinion PET has no central role in primary management of rectal cancer [4]; however, we believe PET will gain increased importance in management of rectal cancer in the future.

Biologically targeted agents for adjuvant and neoadjuvant treatment are promising treatment options; however, patient selection and prediction of treatment effects remain problematic [5].

The wide variations in practice for preoperative management of rectal cancer should alert national and international rectal cancer experts as well as health care administrators. This will influence health care costs, side effects, quality of life, local recurrence, and cancer-specific survival.

Open Access This article is distributed under the terms of the Creative Commons Attribution Noncommercial License which permits any noncommercial use, distribution, and reproduction in any medium, provided the original author(s) and source are credited.

\section{References}

1. Hottenrott C (2010) Optimizing preoperative management of rectal cancer. World J Surg. doi:10.1007/s00268-010-0930-5

2. Augestad KM, Lindsetmo RO, Stulberg J et al (2010) International preoperative rectal cancer management: staging, neoadjuvant treatment, and impact of multidisciplinary teams. World J Surg 34:2689-2700

3. Beets-Tan RG, Beets GL, Vliegen RF et al (2001) Accuracy of magnetic resonance imaging in prediction of tumour-free resection margin in rectal cancer surgery. Lancet 357:497-504

4. McDermott S, Skehan SJ (2010) Whole body imaging in the abdominal cancer patient: pitfalls of PET-CT. Abdom Imaging 35:55-69

5. Roock WD, Vriendt VD, Normanno N et al (2010) KRAS, BRAF, PIK3CA, and PTEN mutations: implications for targeted therapies in metastatic colorectal cancer. Lancet Oncol Dec 14 [Epub ahead of print] 